\title{
Comparative Study of Student-Led Objective Tutorials versus Traditional Tutorials in Undergraduate Pharmacology Teaching in an Indian Medical School
}

\author{
Manoor Narasimha Sachidananda Adiga ${ }^{1, \odot}$ Swathi Acharya ${ }^{1, \odot}$ Rajendra Holla ${ }^{1, \odot}$ \\ ${ }^{1}$ Department of Pharmacology, K.S. Hegde Medical Academy, \\ Nitte (Deemed to be University), Deralakatte, Mangalore, \\ Karnataka, India

\begin{abstract}
Address for correspondence Swathi Acharya, MBBS, MD, Department of Pharmacology, K.S. Hegde Medical Academy, Nitte (Deemed to be University), Deralakattte, Mangalore 575018,
\end{abstract} \\ Karnataka, India (e-mail: swathiacharya@nitte.edu.in).
}

\begin{abstract}
Introduction The drawback of conventional tutorials (CTs) stresses the need for a tutorial with more active participation from students. Student-led objective tutorial provides an opportunity for active learning and makes student responsible. Hence, the effectiveness of student-led objective tutorial (SLOT) with CT in teaching pharmacology for II MBBS students was evaluated in this study.

Materials and Methods In this study, 157 students were divided into three groups and further allocated to SLOT and CT subgroup equally. The effectiveness of the tutorial was evaluated objectively by comparing pretest and posttest scores as well as mean scores.

Results Pretest and posttest scores in SLOT were $3.343 \pm 1.347$ versus $4.8750 \pm$ 1.750 and in CT were $3.2500 \pm 1.690$ versus $4.5781 \pm 1.883$, both type of the tutorials have shown the statistically significant improvement in the scores. The mean score in the SLOT group was $13.6711 \pm 3.47712$ compared with $12.1842 \pm 3.50128$ in the CT group showing statistically significantly $(U=2171.50, p=0.008)$ higher score in SLOT. Feedback regarding the type of tutorial indicating SLOT was better and preferred

Keywords

- conventional tutorial

- student-led objective tutorial

- pharmacology among the students compared with CT. It is more interesting, helps in active learning of the subject, and encourages student to participate actively in learning process.

Conclusion SLOT and CT both improve the learning pharmacology in II MBBS students; however, SLOT being an innovative method will help in active participation of students and increases the focus of the student on particular topic in teaching.
\end{abstract}

\section{Introduction}

Pharmacology is a subject requiring an in-depth understanding of the basic concepts that need to be applied later while dealing with varied clinical situations. To achieve this students should be engaged in learning activities that enhance a deeper understanding of course content through skill development. ${ }^{1,2}$ The lecture sessions planned for teaching larger groups of students, which remain to be the most common instructional design, are mostly passive. ${ }^{1}$ Lectures alone are a poor means of transferring or acquiring information and also are less effective in skill development. Students should, therefore, be encouraged to learn in small groups through
DOI https://doi.org/

$10.1055 / \mathrm{s}-0040-1705670$

ISSN 2582-4287. peer and faculty interaction. ${ }^{3}$ Tutorials are one such small group teaching-learning strategy used in medical school.

A tutorial is a class in which one or more instructor provides intensive instruction on some subject to a small group. ${ }^{4}$ In a medical school, tutorial sessions were imparted to develop or test their ideas, clarify the materials presented in the didactic lectures, apply general concepts to the solutions of specific problems. The tutorial sessions could also be planned to define new questions or to derive solutions to them and hence encourage students in self-learning. ${ }^{5}$ The drawbacks of the conventional tutorial (CT) are lack of active and full participation by students, passive learning strategies and lack of opportunity for teamwork. To make tutorial sessions
License terms

(Deemed to be University) 
effective, there is always a need to look critically into the drawbacks and rectify them.

Student-led objective tutorial (SLOT) is one such attempt which may be addressed by making small working groups, providing an opportunity for active learning and making them responsible for presenting the given topic through visual aids wherein their peers will critically evaluate the content and other aspects of the assigned task.

In learner-centered education the students are engaged in activity that produces a deeper understanding of the course content through skill development. ${ }^{6}$ They learn more and better when they are involved in active learning than passive recipients of instruction. ${ }^{7}$ In this session, the onus lies on the students wherein the role of lecturer shifts from teaching to the facilitator. As per Savery and Duffy, learning occurs when students are encouraged and expected to think critically and creatively within the learning environment through multiple interactions. ${ }^{8}$ With this background, the study was planned to compare the effectiveness of student-led objective tutorial with CT in teaching pharmacology of central nervous system (CNS) for II MBBS students in an Indian Medical School.

\section{Materials and Methods}

This prospective study was conducted in the Department of Pharmacology of a medical college in the southern part of India. After obtaining approval by the Institutional Ethics Committee, the study was performed during May-June 2018. The study participants were the fourth term, medical undergraduates, who voluntarily agreed to participate in the two types of tutorials.

\section{Group Assignment}

We divided the entire batch of 157 students into three groups (50-55) like Group A: Roll no 1 to 50, Group B: Roll no 55 to 100 and Group C: Roll no 101 to 157, which had the tutorials on three different days of a week, and in each group, we allocated the students into the SLOT and CT subgroup in 1:1 ratio like Group A1 and Group A2. The CNS pharmacology topics were divided into two sessions. Each subgroup of students had both types of tutorials in a gap of 1 week. The study was conducted in four phases, as mentioned below.

The preintervention phase in Week 1 included a pretest of multiple choice questions (MCQs) of the topics involved for both the sessions for that particular group followed by a briefing about the two types of tutorials and allocation into SLOT Group and CT group to each subgroup.

\section{Grouping and Allotment of Topics: Week 2}

1. In the student-led objective tutorial (SLOT) group, in each group five teams were formed from 25 students with each team consisting of five students, and they were given a particular subtopic in CNS pharmacology 1 week before the tutorial session. Each team was asked to prepare five MCQs, that is, one MCQ per team member from the allotted topic. The instruction was given to prepare the MCQ with four options (correct answer and three distractors) the explanation for the answer and other distractors, the aim of choosing the question. One student from the team member was made to present the MCQ during the tutorial session. Scrutinization of these MCQs was done by the facilitators 2 days before the intervention phase.

2. In CT group, each team consists of five students, and they were given same subtopics in the CNS system 1 week before the tutorial session. They were asked to read and come for the tutorials session.

\section{Intervention Phases: Week 3}

The first phase included SLOT group-student-led objective tutorials through MCQs and CT group-teacher-led tutorial sessions.

1. Student-led objective tutorial (SLOT) phase: The MCQ prepared by each team was displayed as a PowerPoint presentation by a team leader, and other students were asked to mark the answer in the given response sheet and scoring for the comparison purpose was performed.

2. In CT phase: Questions in this phase were displayed as a PowerPoint presentation by the teacher, and they were asked to write the answers in the given response sheet, and scoring for the comparison purpose was performed.

After this phase again different sets of subtopics were given to the students for cross over session into other type of tutorial.

\section{Cross Over Session: Week 4}

In this students crossed over to the other type of tutorial. Same procedure was followed for both types of tutorial.

\section{Postintervention Phase}

A posttest of MCQ's involving mixture of critical thinking and recall type which were given in pretest along with feedback through a structured questionnaire about the two types of tutorials was conducted immediately ( - Fig. 1).

\section{Statistical Analysis}

Comparison of mean scores of pretest and posttest of both types of tutorials was done to identify effectiveness of each type of the tutorial session. Mann-Whitney "U" test was applied to identify the statistical significance.

Comparison of intervention phase assessment mean scores between both type of tutorial was done by independent $t$-test.

\section{Results}

A total of 157 students were enrolled in the study. Among these, 138 students participated in the study. A total of 76 students participated in both types of tutorials, 34 students participated in only in SLOT, and around 28 in CT (-Fig. 2).

The pretest and posttest conducted carried questions of 10 marks each for SLOT and CT topics allotted for the candidates of each group. The mean pretest score versus posttest score in SLOT group was $3.343 \pm 1.347$ versus $4.8750 \pm 1.750$, and that 


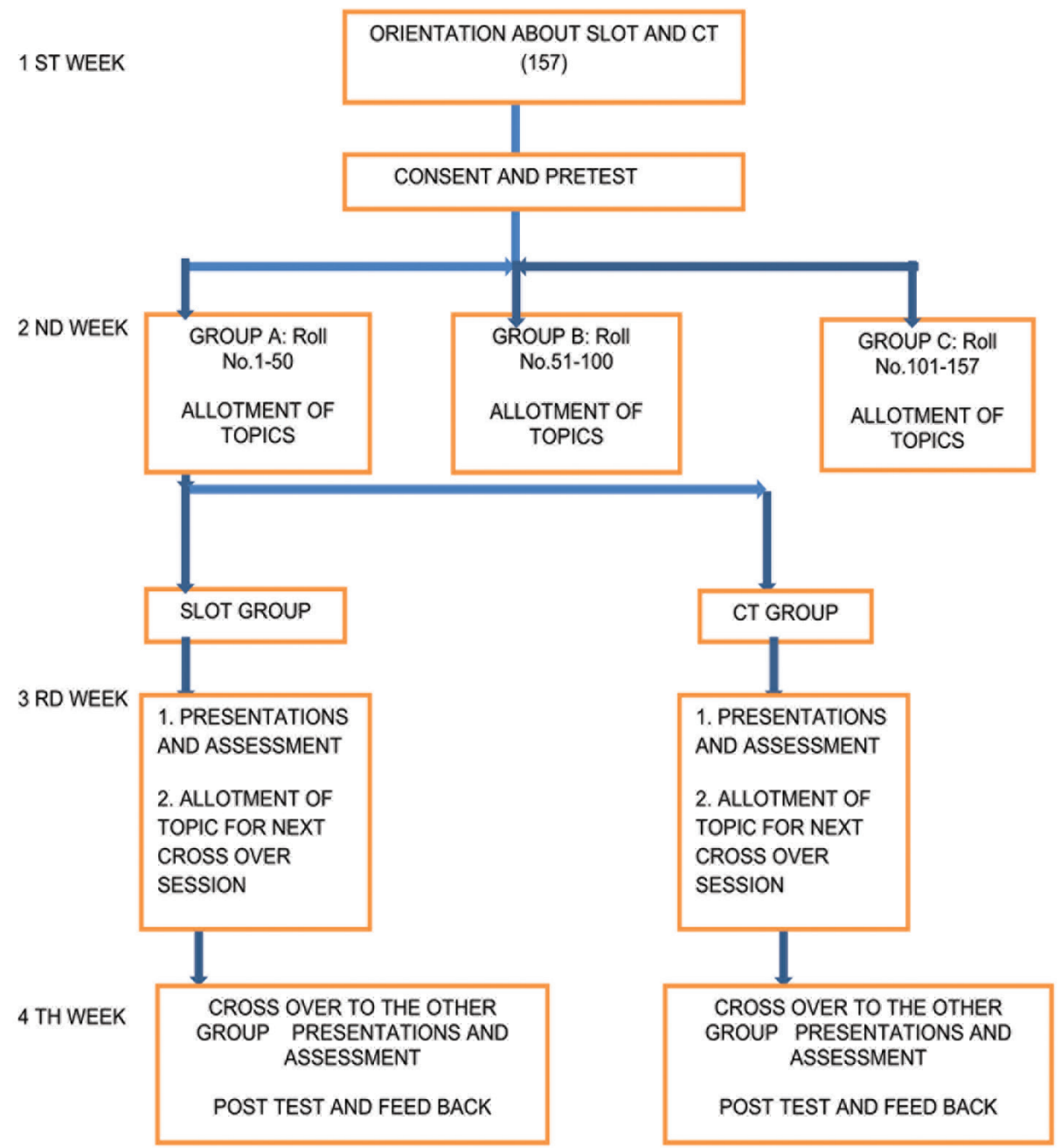

Fig. 1 Flowchart depicting the different phases of the project.

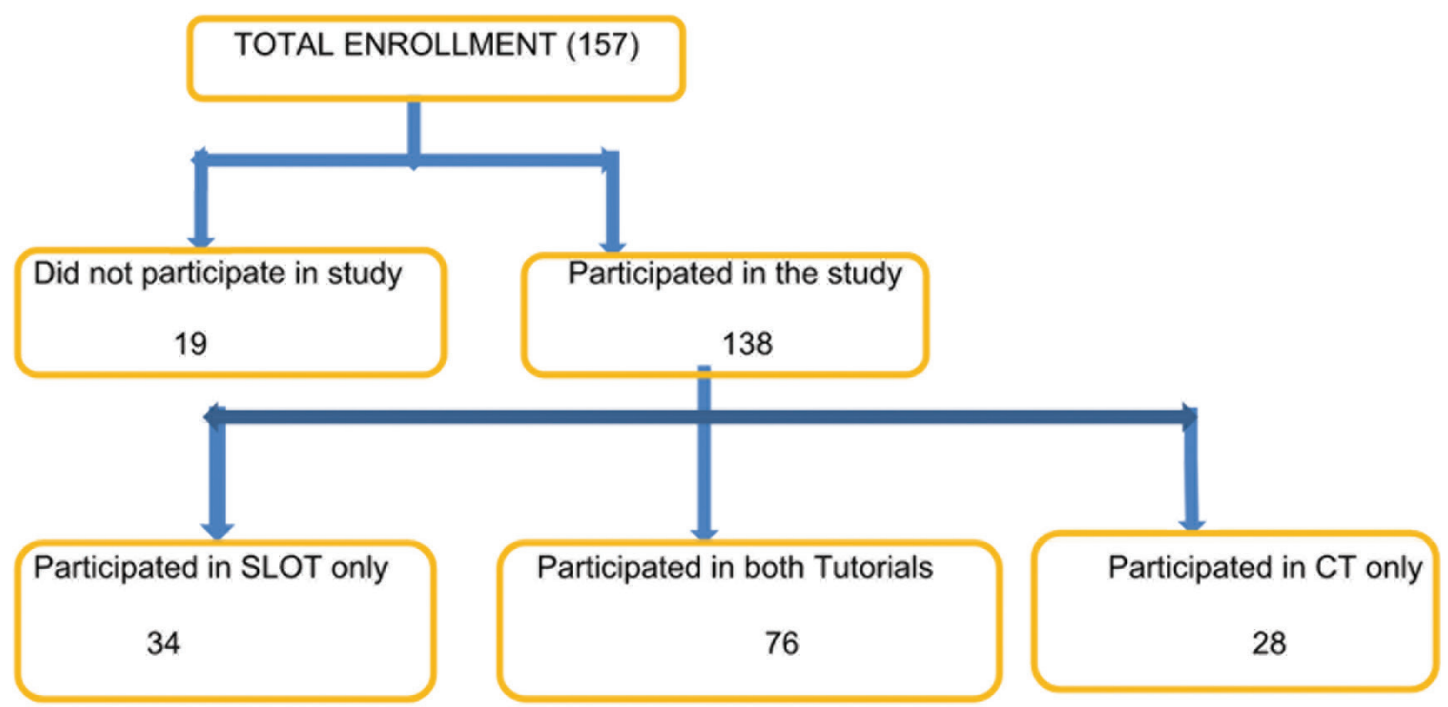

Fig. 2 Showing enrollment and participation of students. 
of the CT group was $3.2500 \pm 1.690$ versus $4.5781 \pm 1.883$. The results seem to indicate that the posttest shows an increase in the score (average rank of 31.12 vs. 17.77 in the case of SLOT and 34.41 vs. 22.37 in the case of CT). The Wilcoxon signedrank test shows that the observed difference between both measurements was significant $(p=0.001$; - Table 1$)$.

The effectiveness of each module was analyzed by scoring the performance in each module of tutorials in a given response sheet which carried a maximum marks of 25 . The mean scores of both the groups were analyzed using Mann-Whitney $U$ test. The mean score in the SLOT group was $13.6711 \pm 3.47712$ compared with $12.1842 \pm 3.50128$ in the CT group ( - Table 2 ), showing statistically significant $(\mathrm{U}=2171.50, p=0.008)$ higher score in SLOT than CT, which signifies SLOT method is superior to that of the CT.

The majority of the students agreed that SLOT helped in understanding the topic in a better way, made tutorials more attractive (85\%), helped in active learning of the subject (84\%), and encouraged them to participate actively (28.12\%). Students also expressed that these types of SLOT will help them to solve MCQs of the competitive exams in a better way than the CT module (71 vs. $80 \%$ ), and they also felt these types of tutorials should be conducted regularly in the future. It will help them to reemphasize the essential aspects of the chapter. (61 vs. $72 \%$ ). However, some students expressed that SLOT was time-consuming and required much prior preparation by the students, and questions were not of standard quality. Some students felt that in $\mathrm{CT}$, there was no active participation from students (40\%), it was boring compared with SLOT (-Table 3-5).

\section{Discussion}

The present study evaluated the effectiveness of SLOT and $\mathrm{CT}$ in teaching pharmacology for MBBS students and it was observed that both types of tutorials showed significant improvement in posttest scores compared with pretest scores. This may be substantiated by the fact that introduction of new system triggered interest in the students for learning to see the difference between the different types of tutorials. Previous studies have shown varied response to SLOT. Arora and Hashilkar study concluded that there was no difference in the posttest scores. ${ }^{9}$ While Sukhlecha et al ${ }^{10}$ opined that there was significant increase in the scores only in SLOT group.

We also compared the effectiveness of each module separately by comparing scores for the tutorial class. The mean scores in SLOT group was significantly higher compared with the CT group, similar to the study conducted by Arora and Hashilkar and Sukhlecha et al.9,10This could be due to various factors like interactive learning through active participation among the students thus improving the knowledge retention and $^{11}$ self-directed learning. ${ }^{2}$ It also helped in understanding the course content in depth, helped to concentrate on the important aspects of the topic, as well as developed critical thinking. ${ }^{12}$

Feedback on different modules revealed that SLOT was the preferred mode of tutorials opted by students. Active participation and active learning were the two aspects of SLOT which made it very interesting for the students. Incorporation of SLOT module in the curriculum was also suggested by the students. They also opined that SLOT will help them in preparing for competitive examination in the future. These findings were similar to the other study findings where peer tutoring can be more appealing with a constructive educational opportunity for the students' academic development.9.13 The preference could also be due to increase in students' self-directedness in small and medium size groups than in large groups.${ }^{14}$ Introducing SLOT into the existing curriculum is one of the approaches that would make teaching in pharmacology more student-centered and exciting.

Students opined that CT helped them to understand the topic and revise the topics effectively but they felt it was boring as there was no active participation from students. This may be due to lack of motivation to the students for self-directed learning and can be improved by the guidance and intervention by the tutor.

The SLOT requires more contribution from the students to conduct it with their active involvement. Framing MCQs for a given topic requires the student to read the topic thoroughly and to understand the various aspects of the topic

Table 1 Comparison of pretest and posttest of SLOT and CT scores

\begin{tabular}{|l|l|l|l|l|}
\hline Groups & Groups & $N$ & Mean \pm SD & $p$-Value \\
\hline \multirow{2}{*}{ SLOT } & Pretest & 76 & $3.3 \pm 1.3$ & $0.001^{\mathrm{a}}$ \\
\cline { 2 - 5 } & Posttest & 76 & $4.9 \pm 1.7$ & $0.001^{\mathrm{a}}$ \\
\hline \multirow{2}{*}{ CT } & Pretest & 76 & $3.2 \pm 1.6$ & \\
\cline { 2 - 4 } & Posttest & 76 & $4.7 \pm 1.9$ & \\
\hline
\end{tabular}

Abbreviations: CT, conventional tutorial; SD, standard deviation; SLOT, student-led objective tutorial.

a Statistical significance set at 0.05 .

Table 2 Comparison of intervention phase SLOT scores with CT scores

\begin{tabular}{|l|l|l|l|l|}
\hline \multirow{2}{*}{ Scores } & Groups & $N$ & Mean \pm SD & $p$-Value \\
\cline { 2 - 4 } & SLOT & 76 & $13.7 \pm 3.4$ & $0.008^{\text {a }}$ \\
\cline { 2 - 5 } & CT & 76 & $12.2 \pm 3.5$ & \\
\hline
\end{tabular}

Abbreviations: CT, conventional tutorial; SD, standard deviation; SLOT, student-led objective tutorial.

astatistical significance set at 0.05 . 
Table 3 Student feedback on both type of tutorials

\begin{tabular}{|c|c|c|c|c|c|c|c|}
\hline Q. No. & Question & $\begin{array}{l}\text { Tutorial } \\
\text { group }\end{array}$ & $\begin{array}{l}\text { Strongly } \\
\text { agree }\end{array}$ & Agree & No comments & Disagree & Strongly disagree \\
\hline \multirow[t]{2}{*}{ Q1 } & \multirow{2}{*}{$\begin{array}{l}\text { Helped in understanding of the } \\
\text { topic }\end{array}$} & SLOT & $33.1 \%$ & $53.3 \%$ & $10.1 \%$ & $2.9 \%$ & $0 \%$ \\
\hline & & CT & $33.1 \%$ & $46.6 \%$ & $11.6 \%$ & $8.7 \%$ & $0 \%$ \\
\hline \multirow[t]{2}{*}{ Q2 } & \multirow{2}{*}{$\begin{array}{l}\text { Helped in our participation in } \\
\text { tutorials }\end{array}$} & SLOT & $44.7 \%$ & $44.6 \%$ & $10.1 \%$ & $0 \%$ & $0 \%$ \\
\hline & & CT & $26.2 \%$ & $50.4 \%$ & $16.5 \%$ & $11.6 \%$ & $0 \%$ \\
\hline \multirow[t]{2}{*}{ Q3 } & \multirow[t]{2}{*}{ Made tutorial interesting } & SLOT & $39.8 \%$ & $46.6 \%$ & $10.6 \%$ & $2.9 \%$ & $0 \%$ \\
\hline & & CT & $29.1 \%$ & $41.7 \%$ & $17.4 \%$ & $9.7 \%$ & $1.9 \%$ \\
\hline \multirow[t]{2}{*}{ Q4 } & \multirow{2}{*}{$\begin{array}{l}\text { Helped in active learning of the } \\
\text { topic }\end{array}$} & SLOT & $33.9 \%$ & $50.4 \%$ & $12.6 \%$ & $2.9 \%$ & $0 \%$ \\
\hline & & CT & $24.2 \%$ & $45.6 \%$ & $23.3 \%$ & $6.8 \%$ & $0 \%$ \\
\hline \multirow[t]{2}{*}{ Q5 } & \multirow{2}{*}{$\begin{array}{l}\text { Should be part of tutorial in } \\
\text { future }\end{array}$} & SLOT & $40.7 \%$ & $45.6 \%$ & $13.5 \%$ & $0 \%$ & $0 \%$ \\
\hline & & $\mathrm{CT}$ & $30.1 \%$ & $46.6 \%$ & $18.4 \%$ & $2.9 \%$ & $1.94 \%$ \\
\hline \multirow[t]{2}{*}{ Q6 } & \multirow{2}{*}{$\begin{array}{l}\text { Helped in solving MCQ hence } \\
\text { will help in exams and competi- } \\
\text { tive exam }\end{array}$} & SLOT & $48.5 \%$ & $23.3 \%$ & $16.5 \%$ & $1.9 \%$ & $0 \%$ \\
\hline & & $\mathrm{CT}$ & $37.8 \%$ & $43.6 \%$ & $14.5 \%$ & $2.9 \%$ & $0 \%$ \\
\hline \multirow[t]{2}{*}{ Q7 } & \multirow{2}{*}{$\begin{array}{l}\text { Learnt the aspects which could } \\
\text { not be covered in theory class }\end{array}$} & SLOT & $33.0 \%$ & $41.7 \%$ & $21.3 \%$ & $3.8 \%$ & $0 \%$ \\
\hline & & CT & $33.9 \%$ & $41.7 \%$ & $16.5 \%$ & $1.9 \%$ & $0 \%$ \\
\hline \multirow[t]{2}{*}{ Q8 } & \multirow{2}{*}{$\begin{array}{l}\text { Reemphasized on the important } \\
\text { aspects of chapter }\end{array}$} & SLOT & $20.3 \%$ & $41.7 \%$ & $18.4 \%$ & $9.7 \%$ & $0 \%$ \\
\hline & & CT & $26.2 \%$ & $46.6 \%$ & $22.3 \%$ & $4.8 \%$ & $0 \%$ \\
\hline
\end{tabular}

Abbreviations: CT, conventional tutorial; MCQ, multiple choice question; SLOT, student-led objective tutorial.

Table 4 Students responses for open-ended questions on student-led objective tutorials

\begin{tabular}{|l|l|l|}
\hline Liked & $\begin{array}{l}\text { They were able to focus on topic in } \\
\text { better way. }\end{array}$ & $28.1 \%$ \\
\cline { 2 - 3 } & $\begin{array}{l}\text { There was more active participation } \\
\text { by the students. }\end{array}$ & $28.1 \%$ \\
\cline { 2 - 3 } & $\begin{array}{l}\text { Learning experience was better with } \\
\text { this mode of tutorial. }\end{array}$ & $20.3 \%$ \\
\hline Disliked & $\begin{array}{l}\text { They were not able to cover all the } \\
\text { topics. }\end{array}$ & $38.0 \%$ \\
\cline { 2 - 3 } & Process was time consuming. & $9.5 \%$ \\
\cline { 2 - 3 } & $\begin{array}{l}\text { Questions were not of standard } \\
\text { quality. }\end{array}$ & $9.5 \%$ \\
\hline
\end{tabular}

Table 5 Students responses for open-ended questions on conventional tutorial session

\begin{tabular}{|c|c|c|}
\hline \multirow[t]{3}{*}{ Liked } & Better learning experience & $38.9 \%$ \\
\hline & $\begin{array}{l}\text { Helpful for the quick revision of } \\
\text { the topic. }\end{array}$ & $25.4 \%$ \\
\hline & $\begin{array}{l}\text { Helpful for them to learn more } \\
\text { topics. }\end{array}$ & $10.1 \%$ \\
\hline \multirow[t]{3}{*}{ Disliked } & $\begin{array}{l}\text { No active participation from } \\
\text { students. }\end{array}$ & $40 \%$ \\
\hline & Tutorial was boring. & $28 \%$ \\
\hline & $\begin{array}{l}\text { Tutorial should have been con- } \\
\text { ducted at earlier stage. }\end{array}$ & $8 \%$ \\
\hline
\end{tabular}

and summarize the gist of individual topic in a better way. Furthermore, discussing every option of the MCQs helps in improving the reasoning skills of the students. As the students make the presentation using power point, this provides them an opportunity to improve their communication skills. ${ }^{2}$ However, some students expressed that SLOT was time consuming and required a lot of preparation. Such a response is expected with the implementation of any new teaching-learning method, but students engaged in self-directed learning undergo a transformation that begins usually with negative feelings and ends with confidence and skills for lifelong learning. ${ }^{15}$

Students also felt that they were not able to cover the topics completely and some MCQs were not that of standard quality. This could be due to the novel approach, time constraint, and heterogeneous study population. This could be avoided by implementing this in regular teaching and motivating students for self-directed learning. The standards of the MCQs prepared can be improved by facilitator-guided discussions and timely intervention. The above issues can be addressed by establishing rapport with students, allowing adequate time for discussion, and having a good expertise in the topic as suggested by Kassab at al. ${ }^{16}$

\section{Conflict of Interest}

None declared.

\section{Acknowledgment}

We would like to acknowledge the help of Dr. Manohar Bhat for analyzing the data.

\section{References}

1 Badyal DK, Bala S, Kathuria P. Student evaluation of teaching and assessment methods in pharmacology. Indian J Pharmacol 2010;42(2):87-89

2 Sivagnanam G, Saraswathi S, Rajasekaran A. Student-led objective tutorial (SLOT) in medical education. Med Educ Online 2006;11(1):4610 
3 Sprawls P. Evolving models for medical physics education and training: a global perspective. Biomed Imaging Interv J 2008;4(1):e16

4 "tutorial." Merriam-Webster Online Dictionary. Springfield, MA: Merriam Webster; 2006. Available at: http://www. merriam-webster.com. Accessed April 2006

5 JamesR, BaldwinG. Tutoring and demonstrating: a guide for the University of Melbourne. Melbourne: Centre for the Study of Higher Education, The University of Melbourne, Australia; 1997. Available at: http://www.cshe.unimelb.edu.au/ bookpages/chap1.html. Accessed April 2006

6 University of Arizona Teaching Teams Program. How to Create Learner-Centered Courses with Teaching Teams: A Faculty Resource Manual for Participants in the Teaching Teams Program and the Einstein's Protégés Program. Arizona: University of Arizona; 2004. Available at: http://teachingteams.arizona. edu/manual.htm. Accessed April 2006

7 Cross KP. Teaching "For" learning. AAHE Bull 1987;39 (8):3-7

8 Savery JR, Duffy TM. Problem based learning: an instructional model and its constructivist framework. Educ Technol 1995;35:31-37

9 Arora K, Hashilkar NK. Effectiveness of student-led objective tutorials in pharmacology teaching to medical students. Indian J Pharmacol 2016;48(suppl 1):S78-S82
10 Sukhlecha A, Jadav SP, Gosai TR, Balusamy D. Student-led objective tutorials in Pharmacology: an interventional study. Indian J Pharmacol 2016;48(suppl 1) :S83-S88

11 Costa ML, van Rensburg L, Rushton N. Does teaching style matter? A randomised trial of group discussion versus lectures in orthopaedic undergraduate teaching. Med Educ 2007;41(2):214-217

12 Towle A, Cottrell D. Self directed learning. Arch Dis Child 1996;74(4):357-359

13 Sobral DT. Cross-year peer tutoring experience in a medical school: conditions and outcomes for student tutors. Med Educ 2002;36(11):1064-1070

14 Lohman MC, Finkelstein M. Designing groups in problem based learning to promote problem solving skill and self directedness. Instr Sci 2000;28:291-307

15 Lunyk-Child OI, Crooks D, Ellis PJ, Ofosu C, O'Mara L, Rideout E. Self-directed learning: faculty and student perceptions. J Nurs Educ 2001;40(3):116-123

16 Kassab S, Al-Shboul Q, Abu-Hijleh M, Hamdy H. Teaching styles of tutors in a problem-based curriculum: students' and tutors' perception. Med Teach 2006;28(5):460-464 